\title{
ADSORÇÃO MULTICOMPONENTE DE CO2 E CH4 EM CARBONO ATIVADO PARA PROCESSOS DE PURIFICAÇÃO DE BIOGÁS
}

\author{
C.A. ALVES ${ }^{1}$, M. CANTILLO-CASTRILLÓN ${ }^{1}$, M. BASTOS-NETO ${ }^{1}$ e D.C.S. AZEVEDO ${ }^{1}$ \\ ${ }^{1}$ Universidade Federal do Ceará, Departamento de Engenharia Química \\ E-mail para contato: mbn@ufc.br
}

\begin{abstract}
RESUMO - Para ser usado como substituto ao gás natural, o biogás deve passar por um processo de purificação, no qual grande parte de sua composição de dióxido de carbono deve ser retirada para que este não afete de forma negativa o poder calorífico do gás combustível. Apesar de bastante atraentes economicamente, processos de purificação por adsorção dependem fortemente do material adsorvente utilizado, que por sua vez deve apresentar, principalmente, altas capacidades e seletividades. $O$ adsorvente utilizado neste estudo foi especialmente desenvolvido para a purificação de biogás, e revelou uma área superficial específica de $1309 \mathrm{~m}^{2} / \mathrm{g}$ e volume de poros de $0,57 \mathrm{~cm}^{3} / \mathrm{g}$. Foram medidas isotermas de equilíbrio de adsorção de dióxido de carbono e metano puros e em mistura com composição de $55 \% \mathrm{CO}_{2}$ e $45 \% \mathrm{CH}_{4}$. O material adsorvente mostrou-se bastante seletivo ao dióxido de carbono. O modelo de isotermas multicomponente Langmuir Estendido foi ajustado aos dados experimentais satisfatoriamente, indicando boa aplicabilidade para a previsão da coadsorção de misturas nas condições estudadas.
\end{abstract}

\section{INTRODUÇÃO}

O biogás consiste basicamente de uma mistura de metano, $\mathrm{CH}_{4}(50-75 \%)$, e dióxido de carbono, $\mathrm{CO}_{2}(25-45 \%)$, com pequenas frações de sulfeto de hidrogênio e vapor de água, dependendo de sua fonte, produzido a partir da decomposição de matéria orgânica, tais como resíduos agropecuários. O biogás é uma fonte de energia renovável e sua utilização como substituto ao gás natural, que por sua vez é composto por $85-95 \%$ de metano, vem crescendo em todo o mundo. No cenário brasileiro, um de seus maiores potenciais é o uso como gás combustível para veículos (Santos, 2013).

No entanto, para tornar o uso de biogás viável em diversas de suas possíveis aplicações, a composição de dióxido de carbono deve ser significativamente reduzida. A presença de $\mathrm{CO}_{2}$ afeta negativamente o poder calorífico do combustível e por isso o biogás usualmente passa por um processo de enriquecimento de metano ou purificação também conhecido como "upgrading".

Uma técnica promissora e atualmente bastante investigada para a separação de gases em geral é a adsorção em sólidos porosos. A adsorção é um fenômeno de concentração 




espontânea de moléculas ou íons (adsorbato) presentes em uma fase fluida (líquida ou gás), que ocorre na superfície de um material sólido, o adsorvente, em contato com o fluido, o adsortivo (Ruthven, 1984; Rouquerol, 1999).

Entretanto, para uma eficaz implantação de um processo de separação de $\mathrm{CO}_{2}$ por adsorção, é fundamental que o material adsorvente utilizado apresente elevada seletividade para $\mathrm{CO}_{2}$ em relação aos demais constituintes da mistura (principalmente $\mathrm{CH}_{4}$ ), significativa capacidade de adsorção e não apresente perda dessas características em uso estendido e a altas temperaturas.

Adicionalmente, o design de um processo ou de uma unidade de separação envolve a aplicação de modelos matemáticos que representem com precisão os fenômenos que ocorrem simultaneamente (Bastos-Neto, 2011), incluindo a adsorção de uma substância na presença de outras - coadsorção ou adsorção multicomponente. Muitos modelos foram propostos na literatura, desde os mais simples aos mais complexos. O modelo de Langmuir Estendido é um dos mais simples que se conhece, porém apresenta limitações de aplicação por conta de suas considerações (Do, 1998).

Neste estudo pretende-se avaliar a capacidade de adsorção e a seletividade para $\mathrm{CO}_{2} \mathrm{em}$ misturas $\mathrm{CO}_{2}-\mathrm{CH}_{4}$ de um carbono ativado desenvolvido para o tratamento de biogás, o Supersorbon ${ }^{\circledR}$ KM (Donau Carbon Corporation, Alemanha). Além disso, a aplicabilidade do modelo de Langmuir Estendido será avaliada para este sistema.

\section{METODOLOGIA}

\subsection{Caracterização Textural}

A amostra de adsorvente em forma de pellets foi caracterizada através do levantamento de isoterma de adsorção de $\mathrm{N}_{2}$ a $77 \mathrm{~K}$ num Autosorb-1 MP (Quantachrome, EUA), através da qual se estimou a área superficial específica $\left(\mathrm{A}_{\mathrm{BET}}\right)$, o volume total de poros e o tamanho médio de poros do material.

\subsection{Isotermas de Equilíbrio de Adsorção de $\mathrm{CH}_{4}$ e $\mathrm{CO}_{2}$}

Através de ensaios gravimétricos realizados numa balança de suspenção magnética da marca Rubotherm (Bochum, Alemanha), foram medidas isotermas de equilíbrio de adsorção no material escolhido.

O procedimento experimental inicia-se com a regeneração do material adsorvente, na qual a amostra é colocada no interior da célula de medidas da balança e mantida à temperatura de $120{ }^{\circ} \mathrm{C}$, enquanto uma bomba de vácuo desgaseifica a célula, no intuito de remover qualquer espécie química que porventura estivesse previamente adsorvida. Tal procedimento é monitorado através da perda de massa da amostra. Após a regeneração, ajusta-se a temperatura para aquela da medição das isotermas e inicia-se a injeção controlada do adsorbato, de forma a se estabelecer a pressão desejada. A temperatura, a pressão e a variação 


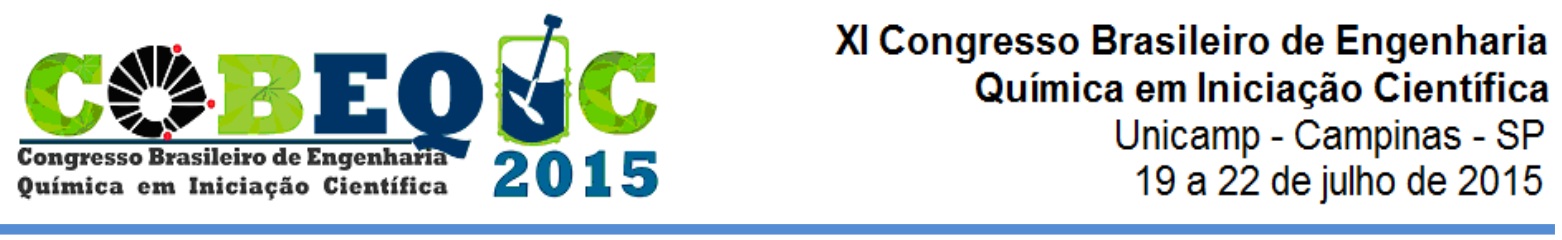

de massa da amostra são registradas, e quando a massa desta deixa de variar, indicando um equilíbrio, pode-se calcular a quantidade de gás adsorvido.

Todas as isotermas foram medidas à $25^{\circ} \mathrm{C}$, numa faixa de pressão variando de 0,01 a 20 bar. No caso da isoterma multicomponente, a mistura consistiu de $55 \%$ de $\mathrm{CH}_{4}$ e $45 \%$ de $\mathrm{CO}_{2}$ em base volumétrica.

Os dados de equilíbrio de adsorção para os gases puros $\mathrm{CO}_{2}$ e $\mathrm{CH}_{4}$ foram ajustados pelo modelo de isoterma de Langmuir (Equação 1) de forma a se obter os valores dos parâmetros de afinidade $(b)$ e capacidade máxima de adsorção $\left({ }^{q_{\max }}\right)$ referente a cada adsorbato, para então serem aplicados no modelo de Langmuir Estendido (Equação 2), a fim de se estimar o comportamento teórico da isoterma multicomponente.

$$
\begin{gathered}
q_{i}=\frac{q_{\max , i} \cdot b_{i} \cdot P_{i}}{1+b_{i} \cdot P_{i}} \\
q_{i}=\frac{q_{\max , i} \cdot b_{i} \cdot P_{i}}{1+\sum_{j=1}^{n} b_{j} \cdot P_{j}}
\end{gathered}
$$

onde $q_{i}$ representa a concentração do componente $i$ adsorvido à uma pressão parcial ${ }^{P_{i}}$.

O somatório das espécies adsorvidas representado no denominador da Equação 2 implica numa redução da quantidade adsorvida de uma determinada espécie quando numa mistura comparada à sua adsorção como substância pura, evidenciando a competição por sítios de adsorção.

As isotermas multicomponentes teórica (estimada pelo modelo de Langmuir Estendido) e experimental foram comparadas com o intuito de se verificar a aplicabilidade deste modelo simplificado para adsorção de misturas em sistemas similares ao deste estudo.

\section{RESULTADOS E DISCUSSÕES}

\subsection{Caracterização Textural do Adsorvente}

A Tabela 1 sumariza as propriedades texturais do carbono ativado utilizado nos experimentos deste trabalho. Pode-se observar que tanto a área superficial específica $\left(\mathrm{A}_{\mathrm{BET}}\right)$ como o volume total de poros apresentam valores apreciáveis, o que indica se tratar de um material potencialmente atraente para adsorção de gases.

Tabela 1 - Propriedades texturais do adsorvente

\begin{tabular}{|c|c|c|c|}
\hline Material & $\begin{array}{c}\text { Área Superficial } \\
\text { Específica }\left(\mathbf{m}^{\mathbf{2}} / \mathbf{g}\right)\end{array}$ & $\begin{array}{c}\text { Volume Total de } \\
\text { Poros }\left(\mathbf{c m}^{\mathbf{3}} \mathbf{g}\right)\end{array}$ & $\begin{array}{c}\text { Tamanho Médio de } \\
\text { Poro (nm) }\end{array}$ \\
\hline Supersorbon ${ }^{\circledR}$ KM & 1309 & 0,57 & 2,83 \\
\hline
\end{tabular}




\subsection{Isotermas de Equilíbrio de Adsorção de $\mathrm{CH}_{4}$ e $\mathrm{CO}_{2}$}

A Figura 1 mostra as isotermas medidas nas condições previamente apresentadas. $\mathrm{O}$ material revelou uma alta capacidade de adsorção de $\mathrm{CO}_{2}$, sendo capaz de adsorver uma quantidade de 5 a 6 vezes maior em comparação a $\mathrm{CH}_{4}$. Este fato é um forte indicativo de que este adsorvente pode apresentar um bom desempenho ao ser usado em um dado processo industrial para separação de dióxido de carbono de metano por adsorção.

A isoterma da mistura mostrou comportamento esperado, numa faixa intermediária aos componentes puros. Sua comparação com a isoterma teórica, estimada por Langmuir Estendido com os parâmetros dos gases puros é exibida na Figura 2.

Pode-se observar que o ajuste foi bastante satisfatório, com erro percentual médio de $4 \%$, o que indica uma boa aplicabilidade do modelo a sistemas similares em condições semelhantes às utilizadas neste estudo.

Figura 1 - Isotermas de monocomponente $\left(\mathrm{CO}_{2}\right.$ e $\mathrm{CH}_{4}$ puros $)$ e multicomponente para mistura de $55 \% \mathrm{CH}_{4}$ e $45 \% \mathrm{CO}_{2}$ a $25{ }^{\circ} \mathrm{C}$. Pontos representam dados experimentais e linhas representam ajuste por Langmuir.

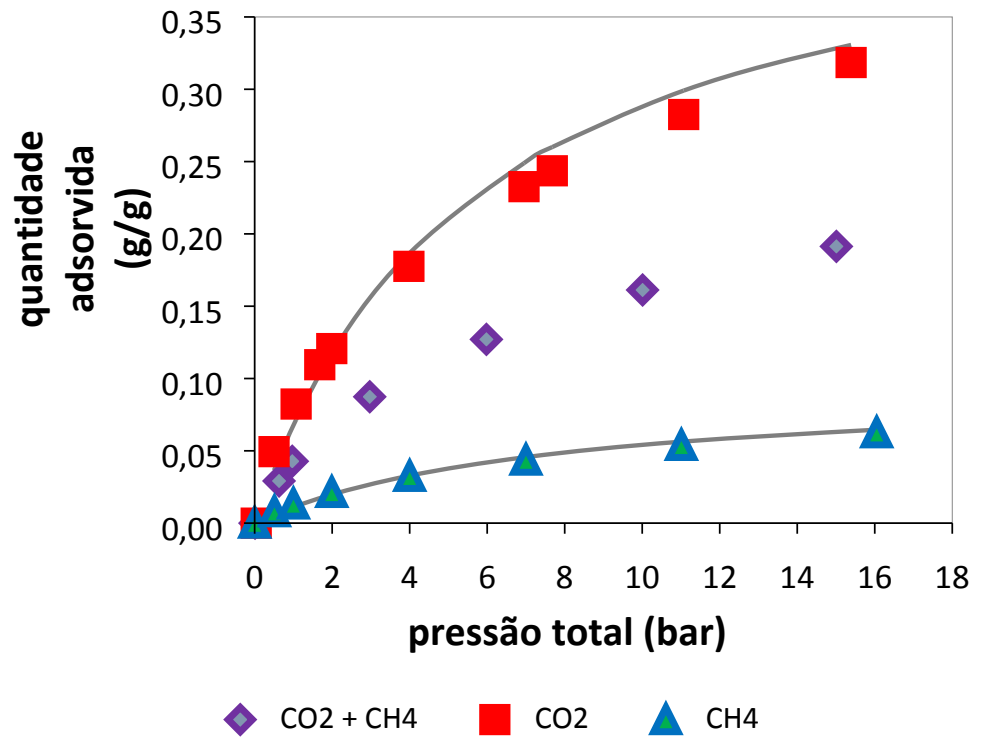


Figura 2 - Comparação entre isoterma multicomponente experimental com estimada por Langmuir Estendido



\section{CONCLUSÕES}

O carbono ativado Supersorbon ${ }^{\circledR}$ KM se mostrou um material viável para o uso na purificação de biogás devido à sua alta seletividade na adsorção de $\mathrm{CO}_{2}$ em detrimento ao $\mathrm{CH}_{4}$ e à sua área superficial e volume de poros relativamente grande quando comparados a outros carvões estudados na literatura (Himeno, 2005), fatores que tendem a proporcionar um bom desempenho de adsorção. Os dados de equilíbrio experimentais das isotermas de $\mathrm{CO}_{2} \mathrm{e}$ $\mathrm{CH}_{4}$ puros foram correlacionadas pela equação de Langmuir Estendido, que, após comparação com a isoterma multicomponente experimental, evidenciou-se um modelo confiável e válido para a predição do comportamento de isotermas de misturas em condições semelhantes às realizas no presente trabalho.

\section{REFERÊNCIAS}

BASTOS-NETO, M. Hydrogen Purification and Storage by Adsorption in Porous Materials, PhD Thesis, Universität Leipzig, 2011.

DO, D.D. Adsorption Analysis: Equilibria and Kinetics (Chemical Engineer Series, Volume 2), Imperial College Press, London, 1998.

HIMENO, S.; KOMATSU, T.; FUGITA, S. High-Pressure Adsorption Equilibria of Methane and Carbon Dioxide on Several Activated Carbons. J. Chem. Eng. Data 2005, 50, 369-376.

PEIXOTO, H. R. Adsorção de Misturas Binárias $\mathrm{CO}_{2} / \mathrm{CH}_{4}$ em Carbono Ativado. Fortaleza: UFC, 2012. Monografia (Graduação). Departamento de Engenharia Química, Universidade Federal do Ceará, Fortaleza, 2012.

ROUQUeROL, F.; ROUQUEROL, J.; SING, K. Adsorption by Powders \& Porous Solids. Academic Press. San Diego, 1999. 
RUTHVEN, D. M. Principles of Adsortion and Adsorption Properties. John Wiley \& Sons. New York, 1984.

SANTOS, M. P. S. Dynamic Study of the Pressure Swing Adsorption Process for Biogas Upgrading and Its Responses to Feed Disturbances. Industrial \& Engineering Chemistry Research Journal, v. 52, p. 5445-5454, 2013. 